\title{
Application of Hybrid Teaching Method Using the MOOC and Verification of its Effectiveness
}

\author{
MyungSuk Lee ${ }^{1} \cdot$ JuGeon Pak ${ }^{2}$ \\ ${ }^{1}$ Tabula Rasa College, Keimyung University, South Korea \\ ${ }^{2}$ Department of Computer Engineering, Keimyung University, South Korea
}

\section{ABSTRACT}

Purpose: Given significant changes in educational environments characterised by the destruction of academic boundaries and the advent of digital natives. We aimed to verify the effectiveness of a hybrid teaching method in improving contemporary learning environments.

Methodology: A descriptive comparative study involving two groups of 68 students: a half used traditional teaching methods and the other half involved in hybrid teaching methods. To verify the effectiveness of the hybrid teaching method in improving the teaching quality. The participants from both groups were asked to answer surveys inquiring about their experiences with the learning processes, their achievements and degree of understanding, perceptions on field experience value, and learner satisfaction.

Results: Reports on hybrid teaching methods showed significant differences in learning and understanding. Field experiences had substantial effects on learning performance and degrees of knowledge acquisition, serving to answer questions of relevance. Students had a higher preference for online over offline courses; they could take classes without time and space constraints. The hybrid methods group were highly satisfied while those in traditional classes had difficulties understanding and questioning concepts. Instructors put excessive effort into digital literacy education and adaptation to smart learning rooms used.

Conclusion: The success of plans to utilise and incorporate MOOCs into learning events, along with introduction of new teaching methods was significant. Education trends will be characterised by customised learning aligned with developments in science and technology, destruction of spatial boundaries between on- and offline activities and emphasis on connections between theory and reality. Digital literacy for both professors and students is critical, as are reviews of educators' roles, and integration of class-room and self-directed learning.

Keywords: Convergent education, Hybrid teaching method, MOOC, Learner-centered learning, Problem-based learning

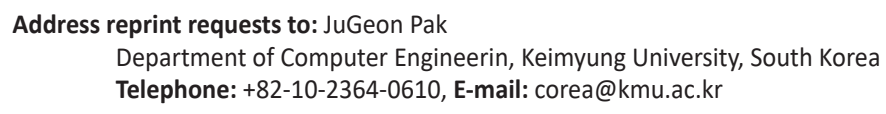

Received: January 9, 2018 Revised: March 14, 2018, May 29, 2018, June 14, 2018 Accepted: June 14, 2018 


\section{INTRODUCTION}

A transition of higher education from traditional lecture-centered classes to greater reliance on experiencebased learning activities has led to restructure of offerings in a way that incorporates recent social and technological trends that promote greater interactive and interdisciplinary approaches to enquiry and practicebased curricula. The introduction of blended learning, the convergence of on-line and face to face educational offerings in recent years has contributed to adaptation of various educational tools and methods. Our recent introduction of the hybrid teaching method is in line with these trends.

Multi-major union can provide a convergence in content within curricula that allow students to take a variety of traditional disciplines that belong to independent disciplines including those at Oxford, Pennsylvania, and Cornell University. The curriculum has a convergent goal, but individual subjects often do not go beyond the existing academic framework. On the other hand, a multi-disciplinary integration type diverse discipline offerings are organised into one topic that allows for integration of content through processes that realise convergence of applied concepts. ChungAng, Yonsei and Hanyang University in Korea use this integrated approach. In the latter it is difficult for instructors to re-orient their values to prepare for classes different from their expertise or to involve two or more instructors in running a single course. Various measures are needed to ensure a successful implementation.

Korean students' experiences tend towards teacher centredness and passiveness and thus suffer from lack of potential for interaction. As a Massive Open Online Course(MOOC) is based on connectionism that emphasises mutual exchange, there are a lot of issues, such as those that might emerge from integrated learning events, that students want to resolve with their professor while engaging in learner-centered learning.

The MOOC, which allows anyone to listen to lectures online anytime and anywhere, was originally an option in educational offerings. However, some unplanned hurdles of the MOOC - absence of compulsion, difficulties for both professors and students to interact with each other, and the meagre rate of course completions, less than $10 \%$, have raised doubt about its educational effects. Therefore, what is attracting attention in Korea as a viable alternative education tool to make up for the shortcomings of the MOOC is the 'flipped learning' approach.

Park's(2016) study searched for problem-oriented subject matter in the operation of the Korea Massive Open Online Course(K-MOOC), suggesting the need to establish diverse profit and operating models based on the nature of education to expand educational opportunities. Lee(2017) studied the role of MOOC and implications for K-MOOC operation. Although MOOC is a paradigm shift in higher education, involving credit recognition, reversal of higher education delivery, decomposition of higher education, it is necessary to utilise MOOC in various ways. Preparatory courses for first-year students have been proposed.

A multilateral review on the operation of online education programs, including MOOC, OCW(Open Course Ware), and Minerva School will be required along with further studies on the possibility of class innovations and effective operational plans. The world of education needs to be prepared and embrace the 4th Industrial Revolution in a comprehensive and integrated manner even though we are not sure how it is going to affect the education processes. Adopting change in education will help strengthen our identity; this study is significant in 
exploring and applying new teaching tools and methods in the era of rapid technological and societal changes.

\section{BACKGROUND}

\section{Current condition and evaluation of online open lectures}

The MOOC, an innovative lecture platform, makes it easier for classroom interactions between teachers and learners or between learners. Other online lectures let learners listen passively. The MOOC is free and this has caused significant repercussions from renowned college professors. The rate of uptake of MOOC is lower than expected; a survey in Lee's(2016) study showed lower than $0.18 \%$ and technical limitations contribute to the extent of uptake. Developing tools for analysis of learning outcomes and the nature of technological advancement will lead to better understanding. The usability of the MOOC will increase over time and contribute to student preparation for the future. Developing specific plans to include the MOOC in college curricula will be a genuine solution to sharing educational resources.

\section{MOOC utilisation plan}

K-MOOC, the localised design MOOC in Korea allows for few comments to be posted in debate rooms, reflecting this Korean tendency to passive learning processes. Designs that encourage passive learning are not likely to cause students to actively participate in the learning events offered in MOOC no matter how potentially diverse and exciting they may be. Therefore, it is necessary to localise the usage of MOOC to match the Korean students' needs, particularly in offline courses.

However, for the MOOC-based classes to be useful, the role of teachers is vital. Teachers should give detailed attention and advice to students to facilitate student learning through the use of the MOOC. In offline classes, interactions with learners and constant help for their direction of activity need to be part of the offline classes. When the course of learners' activity deviates from the education goals, teachers need to facilitate re-orientation to the central goal.

The MOOC may be seen as informal learning, basically about understanding an individual leaner's specific experience in life, imparting a unique meaning to that experience through logical inference and interpretation. Thus, informal learning is an object of meaningful interpretation and a beginning point of introspection activity. As a learner's cognitive activity and regard for 'experience,' 'introspection' is of great importance in understanding the concept of informal learning.

A variety of experiences and reflectivelearning obtained in everyday life are not yet adequately acknowledged by established educational institutions. However, learning activities outside the classroom are increasingly linked to regular class activities with the use of the social network services. For example, marketing major students in Indian University share various marketing ideas with other people via the Instagram using snapshots and hashtags(Cha et al., 2014). Positive opinions on Social Network Service(SNS) established among Korean people and subjective knowledge affect the SNS participation, lead to a positive effect on social acceptance. Satisfaction among college students themselves, cultural features and exchange among friends create mutual understanding. Some studies go as far as concluding that the social acceptance has a significant effect on academic achievement arising from informal learning(Cha et al., 2014). 
If learners can learn from lectures at the rate and level that they want through the MOOC, it will be possible to achieve educational objectives sought by teachers. Also, teachers may reorganise MOOC lecture content according to their curricula and include support materials in their lecture rooms. Teachers may design learnercentered activities that improve learners' recognition and knowledge acquisition. Once learners participate in activities of knowledge acquisition and exansive thinking, they may satisfy other intellectual desires through experience and introspection about daily life.

\section{Hybrid teaching method}

A hybrid teaching method used in this instance involved the integration of formal and informal learning with the addition of mastery learning for use in Onoff-line integrated education, achieving knowledge acquisition and expansion of thinking (Lee et al., 2017).

The existing lecturer-led class has the potential advantage of knowledge transfer and content density, but it overlooks the need to recognize the learner's needs and the value of learner-led learning. Flipped and blended learning approaches involve more self - directed learning, but disadvantages that appear when badly designed include the potential for learning density, opportunity for teacher feedback, and potential for diminished class concentration. Hybrid teaching models have been studied as a way to overcome the shortcomings of existing teaching methods while developing their merits.

The model designed in this study for hybrid teaching method distinguishes formal learning classroom activities from less formal self-directed learning with the MOOC utilised for preview and review. After the formal structured classroom learning, learners are more autonomous, or experience/introspection, freely on a given subject. In this step, learners experience spontaneously and proactively both offline and online, which is followed by introspection on their learning experience. The model designed for hybrid teaching method is presented in Figure 1.

Formal learning sessions include the acquisition of

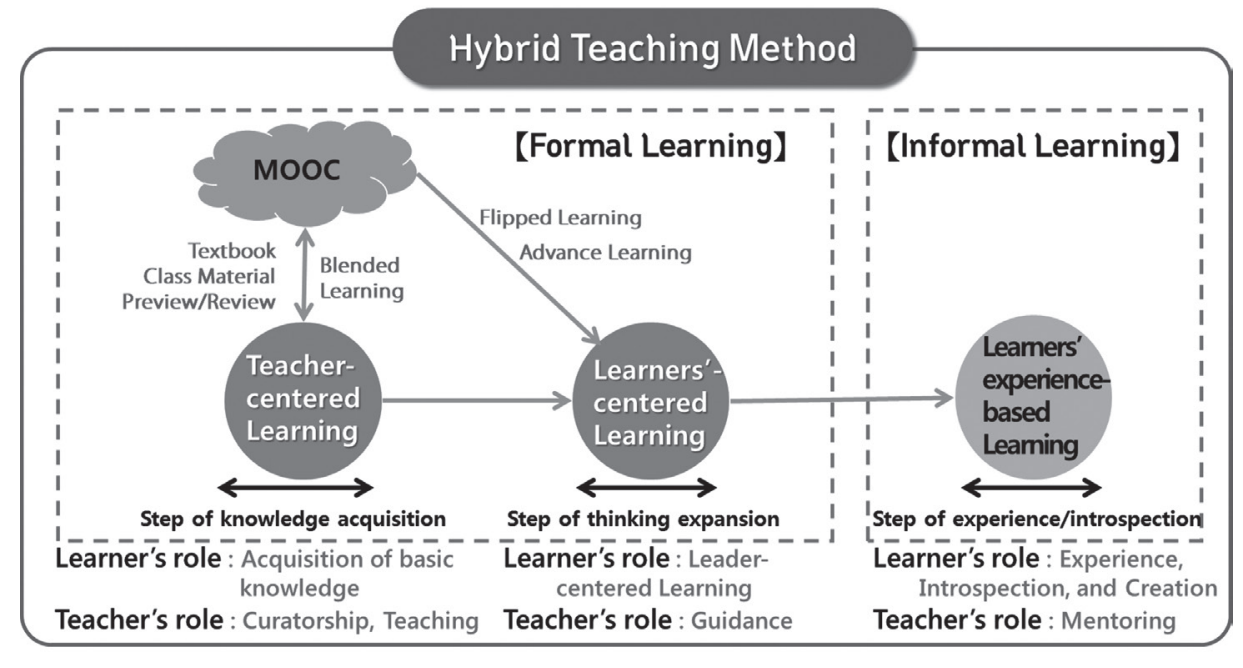

Figure 1. The model designed for the hybrid teaching method 
specific knowledge and expansion of thinking. The acquisition of knowledge also focuses on the contribution of teachers as resource people in the learning process, utilising the MOOC for the textbook, class materials, and preview/review. As for teacher-centered lectures, it is possible to adjust their level of input according to the feedback from learners and thus enhance the educational outcomes for individuals. Relevant resources such as lectures may not only help to expand understanding of the MOOC but also induce interest among learners, promoting more learner-centered activities.

The expansion of thinking is presented through learner-centered learning activities such as discussion, a quiz, and problem-solving activities. One difference from existing flipped learning is that while it is learnercentered the role of teachers is still emphasised. Although activities among learners may enhance learning effect, active facilitative intervention of teachers is essential to achieve educational objectives within the designated time and to induce passive learners to participate. Teachers need to play the role, not as a mere advisor, but as the providers of active guidance.

The formal on/offline learning activity is followed by more process oriented student-centred learning through which learners practise deep learning or application of relevant concepts to the given subject. Learners are exposed to various experiences on a specific topic, both online and offline, and acquire knowledge from those experiences through the steps of introspection. During the phases of multiple experiences and introspection on them, learners may use any form of tools, space, and technology as they want. In informal learning, learners play a leading role while teachers are facilitators and mentors of a learning process that leads to the development of abilities including application of acquired knowledge.

As part of formal learning there is less formal but structured learning that includes a variety of activities outside the class, including everyday experiences and unplanned learning opportunities. These are likely to enhance student participation in their areas of interest. Many experts believe that blended or convergent learning can create an environment that promotes experiments, curiosity, and creativity. The primary goal is to make all students and professors information fluent, develop their enquiring minds and pursue lifelong learning. Educational institutions have experimented with programs that are more flexible, recognising prior competencies and capabilities gained at work eg in the army and involving extracurricular activities. However, there is a lack of systematic methods of officially documenting and evaluating the acquired skills like in regular courses, much less the cost of system and financial support dedicated and suitable to new degree-acquisition methods of learning.

\section{METHODOLOGY}

\section{The hybrid teaching method in 'Science and technology' Classess}

\section{Research: subjects and methods}

The experimental study involved 68 consenting students enrolled in 'Science and Technology' classes over 14 weeks. The comparative study involved students who agreed to participate and signed the personal information agreement. Students were divided into experimental and corresponding groups: Half of students participated in traditional teaching sessions, while the other half were involved in classes using the hybrid teaching method. In 
the last two weeks, the focus was on evaluating the results of the questionnaire and the learning outcomes. The experimental results were considered to be statistically significant when the p-value was less than 0.05 using SPSS version 25 for Windows program.

\section{Existing class management}

Figure 2 illustrates the conceptual diagram of teacher directed on-campus activities using MOOCs. The latter originally involved a video-lecture with little or no interaction within the student group. In a bid to introduce more action oriented learning in the videolecture, quizzes, problem-solving assignments, team-based activities have been adopted. Short video clips(derived from 6 to 12 minutes of MOOCs) were provided with short-cut links to the additional data and information related to the video clips. Experience-based/reflective studies involved students either resolving issues that mostly occur in the field or applying theoretical knowledge to the off-campus field experience. At the conclusion of classroom sessions, teacher-centered activities focus on reflection about essential core concepts and the extent of learner-centered expansion of knowledge. Experience-based/reflective learning activities conducted once every semester enable determination of whether or not the overall goal has been

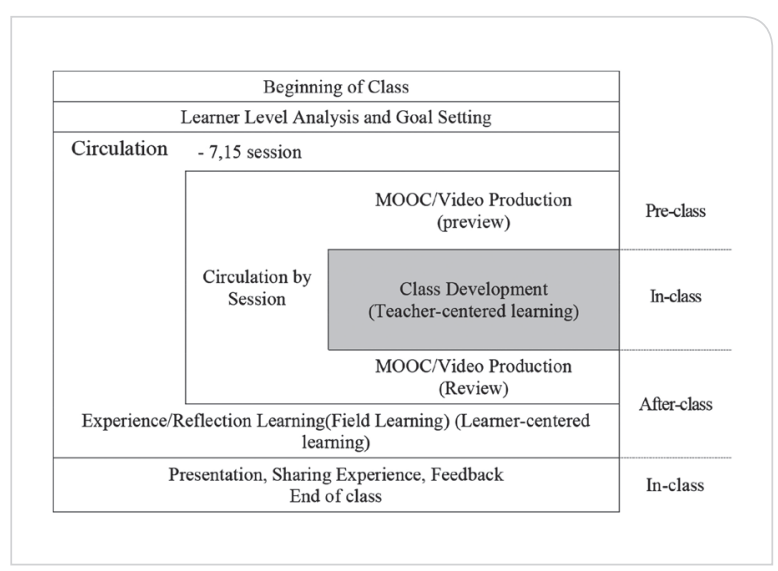

Figure 2. A lesson concept map achieved, through the use of presentations and learners' feedback.

\section{Application of hybrid teaching method}

Figure 3 shows the learning steps using hybrid teaching method. Students are split into different groups in 'science and technology class depending on their academic levels, and the overall class goal is modified accordingly. The students who lack in basic concepts take supplementary learning using the MOOC. The main classroom activity centres on providing an opportunity for achievement of goals through attendance at the professor's lectures. However advanced activity/learning session provide a stage of expanding thought through engagement in more learner-centered activities through practice, experiments and tests on what they learn in class to deepen their learning. Since different students have different styles and methods of learning, they are requested to find their best

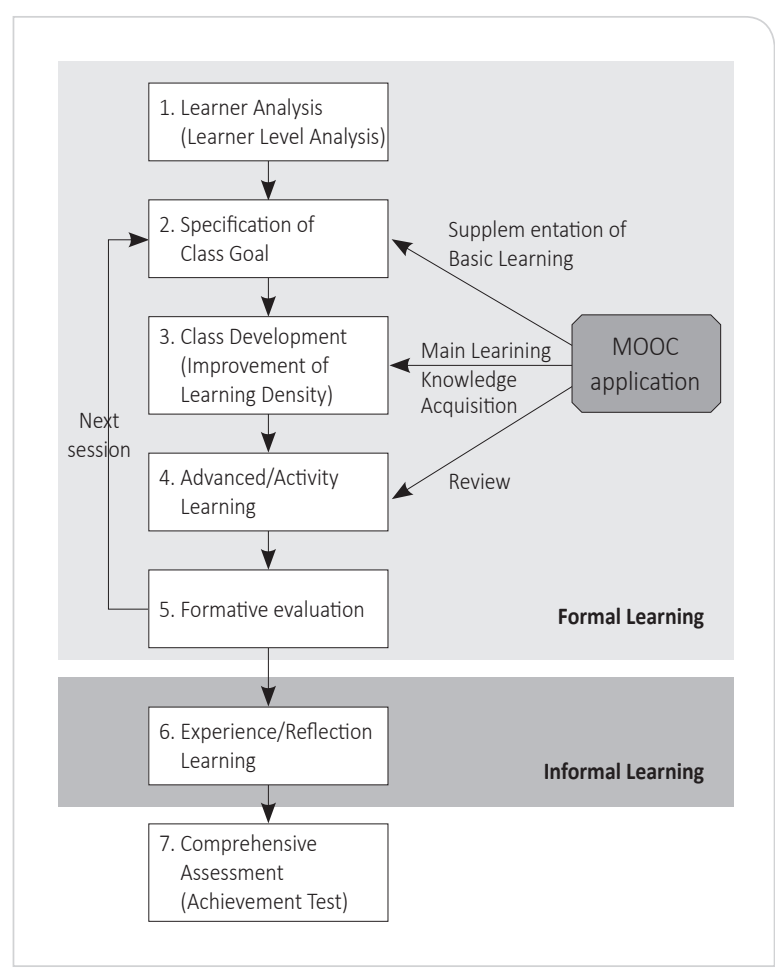

Figure 3. Learning steps for applying hybrid teaching method 
fit among various alternatives, including online learning, offline lecturing, and learner-centered learning such as advanced/activity self-directed learning. Those who successfully pass through the formative evaluation test are considered to have reached a certain level of learning. The formative evaluation test identifies what students know or do not recall. It also intends to complete achieving the class goal(core concepts/knowledge) through additional learning activities. The more traditional educational approach offered by Korean educational institutions is applied up to this point.

As the last stage, students whose scope of thought has been expanded following the experience-based/ reflective learning program are encouraged to develop ideas to resolve field problems by linking what they have learnt in class with actual field problems; this is likely to promote creativity and self-direction in learning through experience-based learning. The summative evaluation focusses on the academic achievement of students comprehensively and thus determines the efficiency of class activities, that is having content and process validity, teacher and student goal orientation, relevance to actual real world situations, practicality and feasibility. The hybrid teaching method can be defined by integration of formal classroom and self-directed learning comprised of both integrated online and offline education as well as experience/reflection educational methods.

\section{CASE STUDIES FOR CLASS}

\section{Learner analysis}

A learner analysis was conducted during the first test session before application of the hybrid teaching method; the results on 68 subjects Test and Control group are as shown in Figure 4. The groups were asked to perform a particular function at a given time. The test results showed extremely low scores throughout all three programs. The $5 \%$ of top-ranked students in test and control groups had similar results. The surveys have secured a certain level of reliability as they have produced the same results on annual surveys.

\section{Content development}

It is difficult to find MOOC content that matches the instructor's choice of relevant content, but lesson aims can directly relate to both the curriculum outcome statements(graduate abilities) and the MOOC video and be made available to learners Figure $5 \mathrm{~A}$ total of three relevant video clips per session with the length of 6 to 15 minutes long have been created( $\mathrm{N}=10$ sessions $)$ to promote students' interest, stimulate active learning and

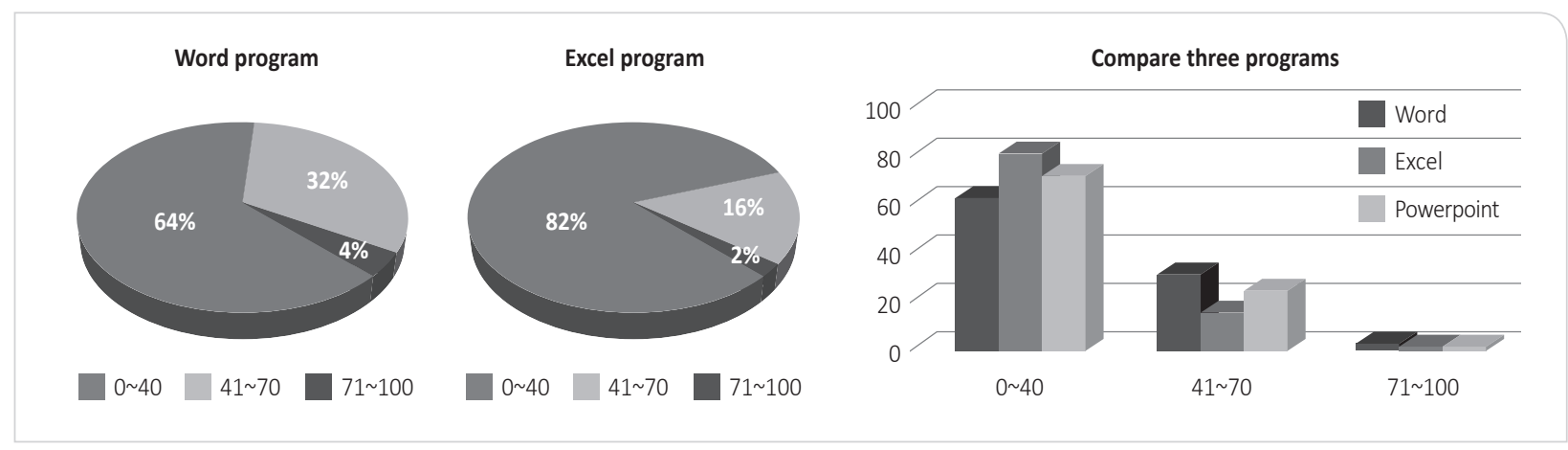

Figure 4. Ability to use the program 


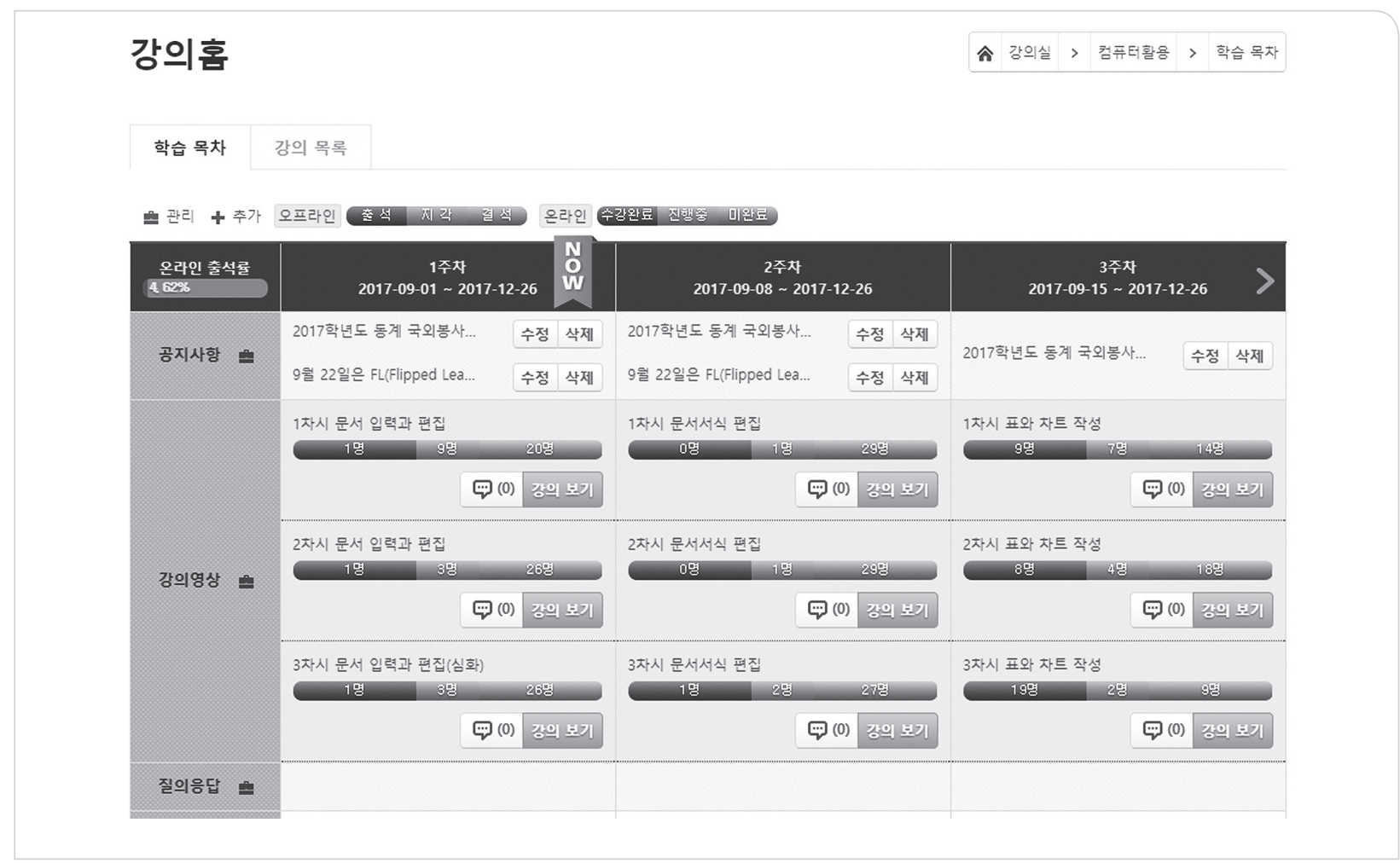

Figure 5. MOOC content development

to deliver the key messages. The Learning Management System(LMS) has also been used to analyse student status of learning, learning dispositions, and learning attitudes.

\section{Advanced/activity learning}

The students were asked to identify field problems during the advanced/activity learning session. They collect the issues and problems that occur in and around them or those that are used in practice. Brainstorming encourages them to come up with solutions for those issues and problems. They also sort out the process of identifying issues and finding solutions, present all

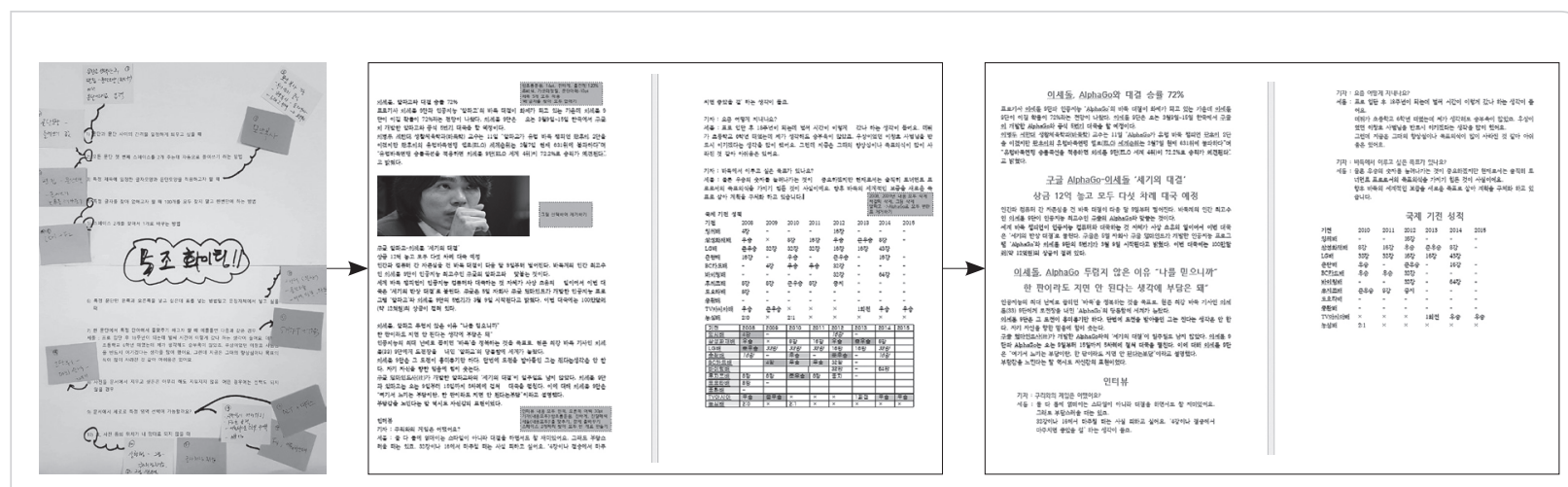

Figure 6. Activity process of learners 
- 과제

$\checkmark$ 성적반영율 적용 과제등록

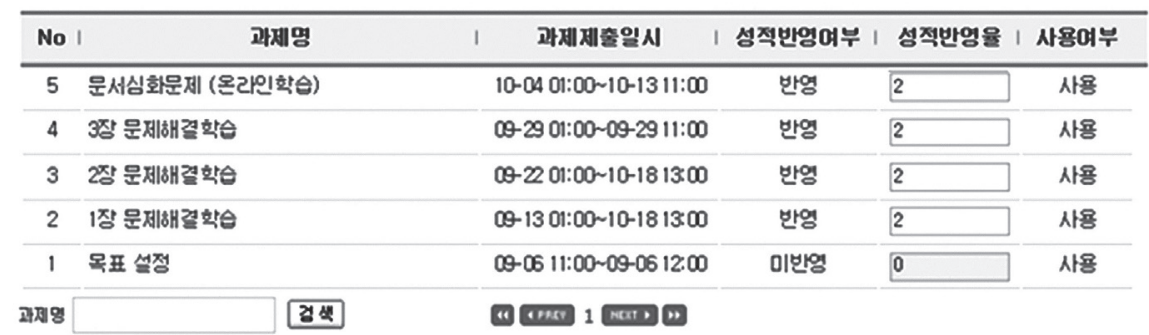

Figure 7. Assessment of formation made every hour

problems to other teams, and see if other teams come up with better solutions for the same problems while engaging in debates, discussions, and presentations as well. Figure 6 shows the activity process of learners.

\section{Formative diagnostic assessment}

Progressive diagnostic assessment deals with a variety of analyses related to learning as the class progresses. As shown in Figure 7 the formative assessment that is conducted in every session evaluates the students on their strengths and weaknesses and provides feedback accordingly so that the students can focus on addressing their weaknesses.

\section{RESEARCH METHODOLOGY}

\section{Study subjects and methods}

The first attempt at application of the hybrid teaching method necessitated verification of effect among student study participants. The 68 liberal art students were split into control and test groups as shown in Figure 8.

\begin{tabular}{cccc}
\hline & & & \\
\hline & Pre-test & Treatment & Post-test \\
\hline Experimental Group & $\mathrm{Q} 1$ & $\mathrm{X}$ & $\mathrm{Q} 2$ \\
\hdashline Control Group(G2) & $\mathrm{Q} 3$ & & $\mathrm{Q} 4$ \\
\hline
\end{tabular}

X1: Application of Hybrid teaching method

Q1, Q3: Pre-test(Academic achievement, Comprehension. Field application) measure

Q2, Q4: Post-test(Academic achievement, Comprehension. Field application) measure

\section{Figure 8. Research design}

The Research Problems(RP) and Hypotheses(Ho) were as follows:

RP 1. What differences in grades are evident in two the groups?

Ho: The students who are taught under the hybrid teaching method will perform as well or better than those in traditional classes.

RP 2. What difference does the hybrid teaching method make regarding comprehension?

Ho: The students who are taught under the hybrid teaching method will have higher levels of comprehension than those in traditional classes.

RP 3. What differences in application of knowledge in the field could be attributed to the design of hybrid teaching methods? 
Table 1. Homogeneity teaching method test

\begin{tabular}{|c|c|c|c|c|c|c|c|}
\hline Teaching method & Group & $\mathbf{N}$ & Avg.(pre) & SD(pre) & Avg.(post) & $\mathbf{F}$ & $p$ \\
\hline \multirow{2}{*}{ Learning Achievement } & Experimental group & 34 & 19.246 & 4.942 & 19.688 & \multirow{2}{*}{2.121} & \multirow{2}{*}{.148} \\
\hline & Control group & 34 & 19.250 & 4.510 & 19.585 & & \\
\hline \multirow{2}{*}{ Learning Understanding } & Experimental group & 34 & 22.264 & 6.146 & 20.025 & \multirow{2}{*}{.402} & \multirow{2}{*}{.536} \\
\hline & Control group & 34 & 22.590 & 6.574 & 21.221 & & \\
\hline \multirow{2}{*}{ Field Application } & Experimental group & 34 & 62.417 & 8.816 & 66.687 & \multirow{2}{*}{1.801} & \multirow{2}{*}{.181} \\
\hline & Control group & 34 & 61.150 & 10.193 & 63.512 & & \\
\hline
\end{tabular}

Ho: The students who are taught under the hybrid teaching method will be better at applying what they have learned to the field than those in traditional classes.

\section{Verification of effects of teaching methods}

The study team obtained the Test Groups averages and standard deviations of academic achievement, comprehension, and field application before and after the use of the hybrid teaching method. The results are shown in (Table 1). In a bid to identify any effects of the hybrid teaching method on learning achievement, learning comprehension, and field application, whether the distribution of each criterion follows the normality or not has been verified, and the regularity of the distribution has been confirmed. The test to verify the homogeneity of the distribution between the test group and the control group has created the significance probabilities of .148, $.536, .180$, respectively, confirming the homogeneity of the distribution since it does not reject a null hypothesis. Comparison of Test and Control groups on the Regression Line Slopes have met the condition that these are identical as the covariate variables between the two groups have no significant interaction effects on the dependent variables. The scatter plots of the post-application grades, as opposed to the pre-application between the two groups, have also confirmed the similar results for both groups.

\section{Analysis of differences between the groups}

The covariance analysis has been conducted with the preliminary test scores and the differences between the scores before and after the application of the new teaching method as the covariates and the dependent variables, respectively. The results have obtained the F-value of 4.043 and the significance probability of .037 with the effect of the preliminary scores under control, indicating that the hybrid teaching method has a statistically significant impact on the grades at the significance level .05 .

Table 2. Hybrid teaching method effect between individuals

\begin{tabular}{|c|c|c|c|c|c|c|}
\hline & Variability source & Sum of squares(SS) & Degree of freedom(df) & Mean square(MS) & $F$ & $\mathbf{P}$ \\
\hline \multirow{3}{*}{$\begin{array}{l}\text { Learning } \\
\text { Achievement }\end{array}$} & covariance & 11892.016 & 1 & 11892.016 & $634.438 * * *$ & \\
\hline & group & 69.623 & 1 & 69.623 & $4.043^{* *}$ & 0.037 \\
\hline & error & 10202.534 & 678 & 14.945 & & \\
\hline \multirow{3}{*}{$\begin{array}{c}\text { Learning } \\
\text { Understanding }\end{array}$} & covariance & 13774.821 & 1 & 13724.821 & $784.615^{* * *}$ & \\
\hline & group & 84.425 & 1 & 84.425 & $4.796 * * *$ & 0.028 \\
\hline & error & 11497.589 & 654 & 16.930 & & \\
\hline \multirow{3}{*}{ Field Application } & covariance & 26545.397 & 1 & 26545.397 & $645.493 * * *$ & \\
\hline & group & 237.942 & 1 & 243.942 & $5.923 * * *$ & 0.014 \\
\hline & error & 25158.574 & 623 & 40.435 & & \\
\hline
\end{tabular}


The same covariance analysis has been performed to verify the effect of the hybrid teaching method on the degree of Comprehension intelligibility. The results have produced the F-value of 4.796 and the significance probability of .028 with the effect of the preliminary degree of clarity under control, indicating that the hybrid teaching method has a statistically significant impact on the grades at the significance level .05 .

The effect of the hybrid teaching method on the field application upon application of the new teaching method has also been examined. The results have produced the F-value of 6.033 and the significance probability of .014 with the effect of the preliminary field application under control, once again confirming the statistically significant effect of the hybrid teaching method the field application. The detailed results are shown in Table 2.

\section{Survey on satisfaction with the teaching method}

The degree of satisfaction among students with the new teaching method was also ascertained. The satisfaction survey comprised 8 questions, including 4 related to benefits, 2 to interest, and the other 2 to the appropriateness of field experience. The questions and answers are described in Table 3. Degrees of satisfaction regarding 'benefits and interest', comparing the new teaching method and application of the hybrid teaching, showed 67\% students found the new method very satisfactory' or $90 \%$ of students expressing a positive review when those who found it 'satisfactory' are included: $29 \%$ of the students found the number of field experience sessions insufficient but $76 \%$ of the students found field experience 'significant'. Overall the hybrid teaching method received a positive review.

Table 3. Satisfaction rating factors and results

\begin{tabular}{|c|c|c|c|c|c|c|c|}
\hline & Survey Questions & & $\begin{array}{l}\text { Not } \\
\text { at all }\end{array}$ & $\begin{array}{l}\text { Not } \\
\text { Really }\end{array}$ & Yes & Absolutely & Sum \\
\hline \multirow{8}{*}{ Benefits } & \multirow{2}{*}{$\begin{array}{l}\text { Would you like to recommend this course because you prefer the used teaching } \\
\text { method? }\end{array}$} & $\mathrm{N}$ & 3 & 4 & 15 & 46 & 68 \\
\hline & & $\%$ & 4.4 & 5.9 & 22.1 & 67.6 & 100 \\
\hline & \multirow{2}{*}{$\begin{array}{l}\text { Were you able to understand quite challenging science and technology program upon } \\
\text { completion of this course? }\end{array}$} & $\mathrm{N}$ & 4 & 2 & 13 & 49 & 68 \\
\hline & & $\%$ & 5.9 & 2.9 & 19.1 & 72.1 & 100 \\
\hline & \multirow{2}{*}{ Did you find the curriculum and used materials helpful? } & N & 3 & 3 & 17 & 45 & 68 \\
\hline & & $\%$ & 4.4 & 4.4 & 25 & 66.2 & 100 \\
\hline & \multirow{2}{*}{$\begin{array}{l}\text { Did you find this teaching method beneficial because you were able to apply what } \\
\text { you learn to your practical life? }\end{array}$} & $\mathrm{N}$ & 3 & 2 & 15 & 48 & 68 \\
\hline & & $\%$ & 4.4 & 2.9 & 22.1 & 70.6 & 100 \\
\hline \multirow{4}{*}{ Interests } & \multirow{2}{*}{ Did you find the teaching method and class exciting? } & $\mathrm{N}$ & 5 & 4 & 19 & 40 & 68 \\
\hline & & $\%$ & 7.4 & 5.9 & 27.9 & 58.8 & 100 \\
\hline & \multirow{2}{*}{ Did you find the lectures easy to understand and enjoyable? } & N & 3 & 5 & 14 & 46 & 68 \\
\hline & & $\%$ & 4.4 & 7.4 & 20.6 & 67.6 & 100 \\
\hline \multirow{4}{*}{$\begin{array}{l}\text { Appropriateness } \\
\text { of field experience }\end{array}$} & \multirow{2}{*}{ Did you find the number of field experience sessions appropriate? } & N & 4 & 20 & 17 & 27 & 68 \\
\hline & & $\%$ & 5.9 & 29.4 & 25 & 39.7 & 100 \\
\hline & \multirow{2}{*}{ Did you find the field experience helpful in solidifying your learning? } & N & 2 & 2 & 12 & 52 & 68 \\
\hline & & $\%$ & 2.9 & 2.9 & 17.6 & 76.5 & 99.9 \\
\hline
\end{tabular}




\section{CONCLUSION}

This study focused on hybrid teaching method previously developed for actual classes and examined its effects from four perspectives - academic achievement, comprehension, perceptions on field experience and class satisfaction when compared with the traditional teaching method.

The students taught under the hybrid teaching model showed significantly higher academic achievement backed by a higher rise in grades compared with those following traditional teaching methods. Hybrid method participants took a gradual approach to handling difficult functions when comprehension was needed. Regarding field application, while one field event may not be enough to identify its effect entirely, Test Group members were shown to struggle to come up with the solution when faced with a major problem while those under the traditional teaching method were shown to 'relinquish' a chance to contribute when encountering a challenging question. With respect to comprehension, the students found it hard to understand the functions outlined in lecture-based classes and struggled to find out where and how to apply what they learned in the field. Test Group students were not very satisfied with the class load.

The professor was able to provide intensive resource sessions for underachieving students, using the MOOC until they met the acceptable level of learning outcomes. They also helped high achieving students adjust to the method of learning, enabling tailor-made learning and improving the relevance of the educational experience. Passive students were shown to actively participate in class through a learner-driven class and field experience while increasingly demonstrating problem-solving with increased interactions with the professor. Each of these elements of learning highlight a desire for further refinement on the teaching method in a more systematic manner.

Several suggestions arose from the research findings and results. First, both professors and students are encouraged to enhance their digital literacy. Utilization of technology productively and innovatively is a part of competencies required in the 21 st century in and out of the workplace. Digital literacy means more than just technical skills and requires an in-depth understanding of the digital environment so that you will be able to intuitively adapt to a new environment and create new ideas with others. A wide variety of options are needed to attain a sufficient level of digital literacy; higher education leaders need to encourage institution-level involvement and support for the development of these competencies.

Second, it is necessary to re-review the roles of educators who are increasingly required to take advantage of advanced teaching methodologies such as project-based learning or problem-based learning. Change needs to occur in a proactive manner given the increasingly frequent use of a variety of education-related technologies, including digital teaching materials and courseware. This paradigm shift toward learner-centered learning transforms or elevates the roles of educators into those of guides and facilitators. This transformation challenge along with the advent of competency-based learning calls for more tailor-made approaches to learning events to meet students' needs. With this technologybased approach spreading and becoming increasingly prevalent, many educational institutions around the world are rethinking the major roles of educators. These changes in education field along with social changes may directly or indirectly influence changes in models of professorships such as the expansion of courses taught by non-tenure-track professors. This has implications for 
the management of curriculum implementation. Third, the formal and less formal learning events need to be integrated. As interest in technology empowers everyday people to learn something about pretty much everything with nothing more than a fingertip contact, there has been an increasing interest in self-driven learning and curiosity-based learning This raises an urgent need to see students as autonomous, self-directed learners, acquiring knowledge in spaces and places beyond the more formal classroom because the curriculum design and learning events promote learners' curiosity and creativity.

The Test Group students taught under the hybrid teaching method have shown consistency in achievement of grades while the Control Group students subjected to the traditional classroom activities demonstrated fluctuations in engagement depending on the level of difficulty of the challenges posed, demanding higher high levels of problem-solving capabilities. However, this topic should be left to further follow-up studies as the new generation of digital natives among learners and educators demand greater access to blended learning that enables them to be more self-directed in their learning. Of critical importance is a focus on the assessment tasks that examine outcomes specific to integration of content and processes across discipline boundaries.

\section{ACKNOWLEDGMENTS}

The authors thank Professor Margaret McMillan for her guidance in preparing this paper for publication.

\section{REFERENCES}

Cha, S. B., Park, S. Y., \& Ku, B. D. (2014). An analysis of the relationship between university students informal learning outcomes with social acceptance, participation, perceived attitude and subjective knowledge based on the structural equation model. Korean Association for Educational Information and Media, 20(4), 675-704.

Choi, K. A. (2016). Tasks for Effective Use of K-MOOC as a Higher Continuing Education. Journal of Lifelong Learning Society, 12(2), 1-24.

Fidalgo-Blanco, A., Sein-Echaluce, M., \& García-Peñalvo, F., (2016). From massive access to cooperation: lessons learned and proven results of a hybrid xMOOC/cMOOC pedagogical approach to MOOCs. International Journal of Educational Technology in Higher Education, 13(1), 1-13.

Future Learn, https://www.futurelearn.com/about-futurelean

Guo, P. J., Kim, J. H., \& Rubin, R. (2014). How video production affects student engagement: An empirical study of MOOC videos. In Proceedings of the first ACM conference on Learning scale conference, 41-50.

Jeong, H. J., \& Kang, I. E. (2011). Study of the development of learner-centered PBL(LC PBL) model in higher education. Korean Association for Learner-centered Curriculum and Instruction, 11(4), 419-448.

Jeong, J. W., \& Song, B. R. (2014). Analyzing learning experience and perception in a blended entrepreneurship training program: A case study. Journal \& Article management System, 26(4), 871-898.

KOCW, http://www.kocw.net/home/kocwStatistics.do

Lee, B. H. (2017). “The analysis of current MOOC trends in the USA major MOOC platforms: the role of MOOCs and implications for K-MOOC operation. The Journal of Educational Information and Media, 23(4), 709-734.

Lee, M. S., \& Bae, E. S. (2017). Development of Hybrid Teaching Method Using MOOCs. International Journal of Intelligent Engineering \& Systems, 10(3), DOI:10.22266.

Lee, M. S., Bae, E. S., \& Song, H. J. (2016). 2015 Higher Education E-Learning Status, Korea Education and Research Information Service. Korea Education \& Research Information Service, Research Report, 45-51.

Online Course Report, http://www.onlinecoursereport.com/

Online class 'MOOC' Where to go? http://blog.naver.com/ scienceall1/220198177870

Park, C. U. (2016). "An Analysis of problems and Subject Matter 
in the Operation of K-MOOC. The Journal of Curriculum Studies, 34(2), 121-141.

Park, S. H. (2016). A Study on Students' Instructional Preferences between Problem-based learning and Teachercentered Learning. Journal of Learner-Centered Curriculum and Instruction, 16(9), 495-515.

Park, S. H., \& Yeoum, M. S. (2007). Teaching-Learning and Educational Engineering, Hakjisa corp., 95-100.

Shin, J. H. (2011). Education method and education engineering, Taeyeoungbook Co., 126-128.

Son, D. H. (2009). "The Basis of Integrative Education \& the Role of University College. Korean Journal of General education, 3(1), 21-32.

Yoo, G. J., \& Kang, B. J. (2005). Education method and education engineering, Chang-Ji Co., 114-116. 